\title{
Comparison of the GRUAN data products for Meisei RS-11G and Vaisala RS92-SGP radiosondes at Tateno $\left(36.06^{\circ} \mathrm{N}, 1^{140.13}{ }^{\circ} \mathrm{E}\right)$, Japan
}

Eriko Kobayashi et al.

Correspondence to: Eriko Kobayashi (eriko-kobayashi@met.kishou.go.jp)

The copyright of individual parts of the supplement might differ from the CC BY 4.0 License. 


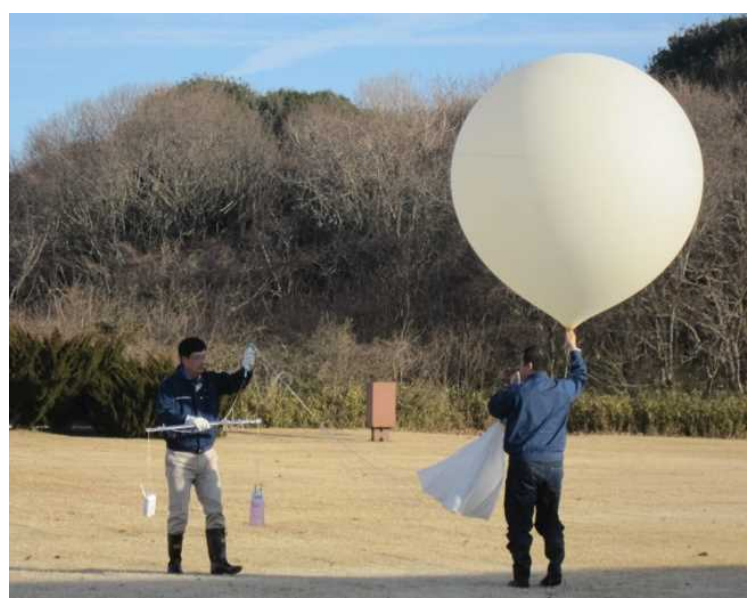

Figure S1: Preparations for a flight launch at 8:30 local time on January 6, 2017. RS-11G and RS92 radiosondes were hung at the two ends of a plastic cardboard rod.
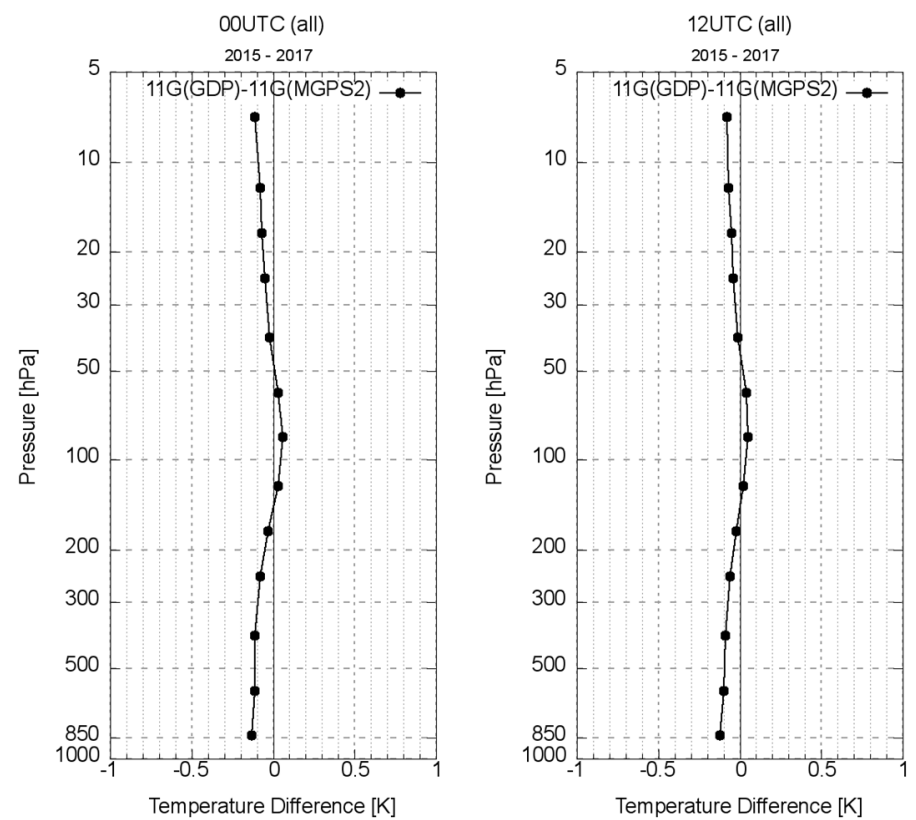

Figure S2: Profiles of mean temperature differences between the RS-11G GDP and RS-11G MGPS2 (RS-11G GDP minus RS-11G MGPS2) for all measurement data. The RS-11G MGPS2 is an RS-11G product produced with the Meisei MGPS2 software.

Figure S2 shows temperature comparison results for the RS-11G GDP and the RS-11G product from the Meisei software MGPS2 (RS-11G MGPS2). The main difference between the RS-11G MGPS2 and the RS-11G GDP for temperature data is that the RS-11G GDP uses an improved procedure to derive raw temperature values from the relationship between radiowave frequency and resistance for the thermistor. 

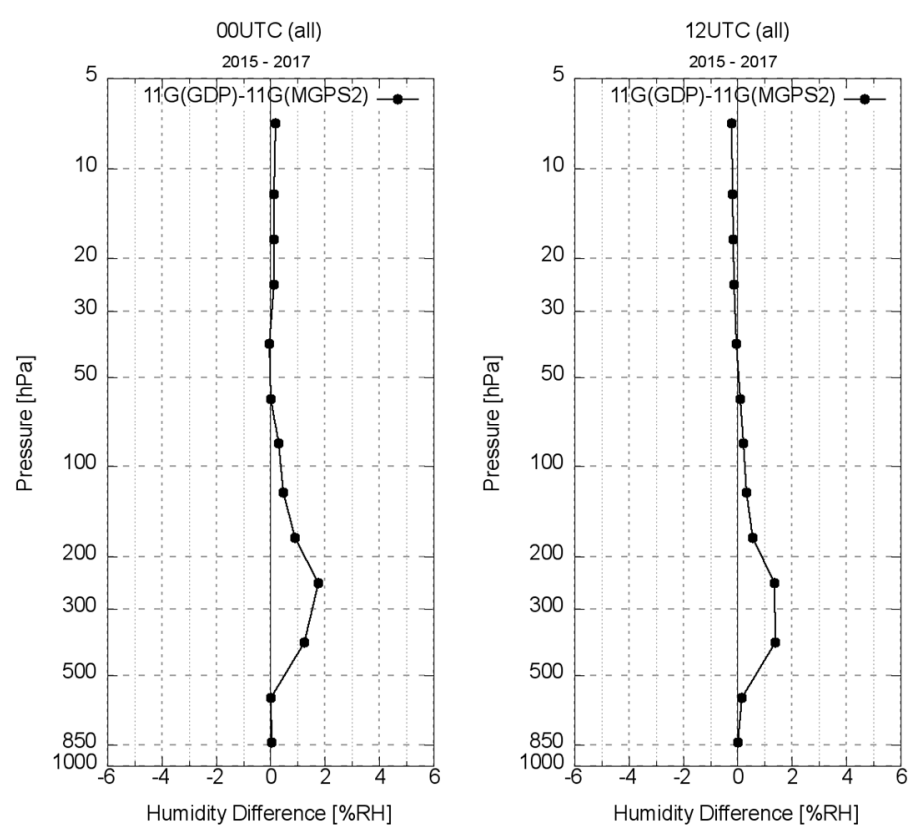

Figure S3: As for Fig. S2, but for RH.

Figure S3 shows RH comparison results for the RS-11G GDP and RS-11G MGPS2. In the RH calculation, the main difference between the RS-11G MGPS2 and RS-11G GDP for RH data is that the RS-11G MGPS2 product does not have corrections using the SHC ground check data. Also, the contamination removal filter for rain and cloud droplets has been improved for the RS-11G GDP. 